\title{
Comparison of Electrophysiological Outcomes of Tethered Cord Syndrome and Spinal Intradural Tumors: A Retrospective Clinical Study
}

\author{
Serhat PUSAT, Cahit KURAL, Ilker SOLMAZ, Caglar TEMIZ, Yunus KACAR, Ozkan TEHLI, Murat KUTLAY, \\ Mehmet DANEYEMEZ, Yusuf IZCI
}

Gulhane Military Medical Academy, Department of Neurosurgery, Ankara, Turkey

This study has been presented at the German Neurosurgery Congress, Dresden, 2013.

\section{ABSTRACT}

AIM: Electrophysiological evaluation of the outcomes of spinal procedures is important for neurosurgeons. Somatosensorial evoked potentials (SSEPS) are used for electrophysiological evaluation of tethered cord syndrome (TCS) and spinal intradural tumors (SIT). The aim of this study was to document the electrophysiological outcomes of surgery for TCS and SIT and to compare the results based on the preoperative diagnosis.

MATERIAL and METHODS: The data of 30 patients, who were operated for TCS and SIT between 2011 and 2013 , were reviewed retrospectively. Surgical release of the spinal cord was performed for TCS and tumor removal was performed for SIT. Median and tibial nerve SSEPs at the left and right sides were measured at preoperative, early and late postoperative periods and compared statistically based on the diagnosis and the time of electrophysiological assessment.

RESULTS: The diagnosis was TCS in 12 (40\%) patients and SIT in 18 (60\%) patients. There was a significant difference between preoperative, and early and late postoperative SSEPs values. Tibial nerve latencies were prolonged in the early postoperative, but shortened in the late postoperative period. In contrast, median nerve latencies were shortened in the early postoperative, but prolonged in the late postoperative period. There was no significant difference between the TCS and SIT groups based on the surgical intervention.

CONCLUSION: Tibial nerve latency may be prolonged in the early postoperative period of TCS and SIT patients. However, electrophysiological changes were not predictive for these patients. Further studies with more patients are needed for other spinal lesions.

KEYWORDS: Electrophysiology, Spinal intradural tumor, Surgery, Tethered cord syndrome

\section{INTRODUCTION}

Tethered cord syndrome (TCS) is a clinical entity in which patients may present with urological and/or neurological symptoms and a low-lying conus medullaris is usually detected with magnetic resonance imaging (MRI) $(1,11,23)$. TCS may be primary or secondary to previous spinal surgeries $(8,16,23)$. Congenital spinal malformations such as split cord malformation (SCM), myelomeningocele, lipomeningocele and dermal sinus tracts are the causes of primary TCS in children and adults $(1,8-11,20,23)$. TCS is generally diagnosed in childhood, but it may also be detected in the adult age group $(1,2,10,20)$. Lumbar hypertrichosis, port-wine staining, and similar cutaneous findings are frequent signs of TCS (10). In addition, urological, orthopaedic and neurological findings 
are frequently associated with TCS in pediatric patients $(1,6,10,23)$. Pain is the most common complaint in adulthood (1). The treatment of TCS is the surgical release of the spinal cord and repair of the associated malformation $(4,13,14,23)$. Electrophysiological studies of the patients in preoperative and postoperative periods are crucial in order to objectively evaluate the patients $(13,15.23)$. Motor evoked potentials (MEPs) and somatosensorial evoked potentials (SSEPs) are the most commonly used tools for the electrophysiological evaluations of TCS patients (15).

Spinal tumors are classified as epidural, intradural extramedullary, or intradural intramedullary based on their anatomical location related to the dura mater and spinal cord $(7,24)$. Extradural tumors are mainly secondary to metastatic disease (24). SITs are uncommon lesions and affect only a minority of the people. However, when these tumors grow, they result in compression of the spinal cord and/or cauda equina, which may cause pain, motor and sensory disturbances, and urological problems (24). About half of all spinal tumors are located intradurally $(3,7)$. Meningioma and schwannoma are the most common extramedullary tumors while astrocytoma and ependymoma are the most common intramedullary tumors $(3,24)$. Extramedullary tumors are usually seen in the middle age group, but intramedullary tumors are frequently observed in pediatric patients (3). Back pain, motor weakness, sphincter disturbances are the main symptoms of SITs $(3,7,17)$. In these patients, MRI is the gold standard for accurate diagnosis. MRI provides useful information about the location, size and characteristics of the tumor. It is also helpful for the planning of surgery (24). The surgical procedure depends on the location of the tumor, but laminectomy or laminotomy is the standard technique to access and remove the tumor. Decompression of the spinal cord and neural structures is the main goal of surgery $(3,21,22,24)$. Careful microsurgical dissection and tumor resection are required in intramedullary tumors as the normal anatomical borders have usually disappeared in these tumors $(3,21,24)$.
The main objective of surgical treatment in TCS and SIT is to preserve the neural structures as much as possible and to prevent the neurological deterioration of the patient $(1,3,11,15,24)$. Electrophysiological studies such as for MEPs and SSEPs are usually performed in preoperative and postoperative periods for the objective assessments of the patients $(5,6)$. These studies may predict the outcome of surgical treatment. SSEPs are generated by stimulation of afferent peripheral nerve fibers by either physiological or electrical techniques. In clinical practice, electrical stimulation is usually administered to elicit the potential $(11,12)$. The usual sites for stimulation are the median nerve in the upper extremities, and the posterior tibial nerve in the lower extremities $(26,28)$. SSEPs may show a lesion involving the somatosensory pathways but the findings should be interpreted along with the neurological examination (18). SSEPs examination may be helpful not only in the diagnosis of spinal or peripheral nerve lesions, but also in the prediction of the prognosis (23). Therefore, findings related to SSEPS must be interpreted and compared carefully with the other neurological findings $(25,26,28)$.

In this retrospective study, we analyzed the preoperative and postoperative median and tibial SSEPs of patients with TCS and SIT. We compared the results statistically and reviewed the current literature on this issue.

\section{MATERIAL and METHODS}

The medical records and electrophysiological data of 30 patients who had been diagnosed with TCS or SIT and undergone surgical treatment at the Department of Neurosurgery, Gulhane Military Medical Academy between January 2011 and December 2013, were retrospectively reviewed. Eighteen patients had a diagnosis of SIT (Figure $1 \mathrm{~A}, \mathrm{~B})$ and 12 patients TCS in preoperative period. Detailed neurological examination, electrophysiological assessment with median and tibial SSEPs and radiological examination

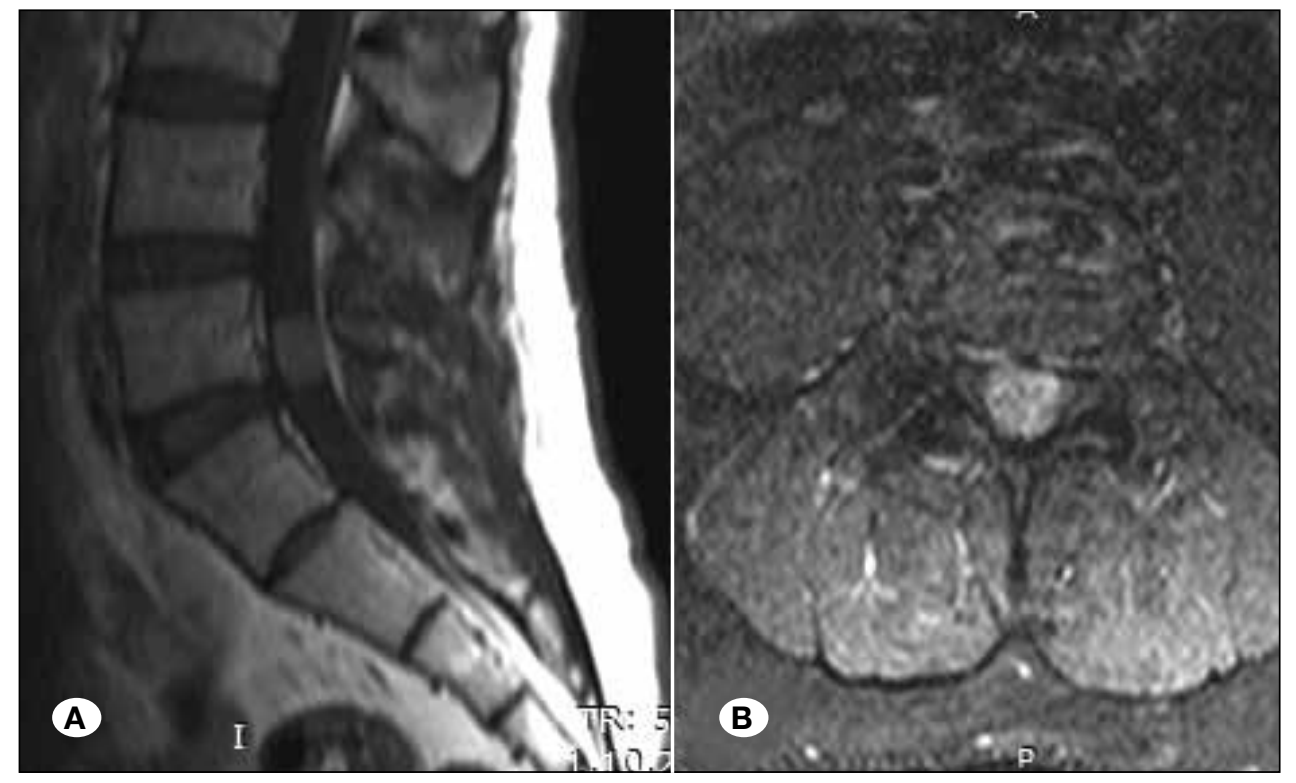

Figure 1: Sagittal (A) and axial (B) MRI scans of a 28 years-old male patient with spinal intradural tumor (SIT) show hyperintense contrastenhancing tumor at the L5 level. The diagnosis was schwannoma. 
with spinal $\mathrm{MRI}$ were performed in all patients in the preoperative and postoperative periods. Medtronic-Dantec $₫$ (Denmark) was used with integrated electrical stimulators and electrodes for electrophysiological studies. SSEPs were obtained by stimulation from the median and posterior tibial nerves and recordings were made from the somatosensory cortex. We used the P37 peak for the median nerve response, and N20 for the posterior tibial nerve. Preoperative computed tomography (CT) was also used in the assessment of bone lesions. Preoperative and postoperative tibial SSEPs were performed and interpreted by the same electrophysiologist in all patients.

Untethering the spinal cord was the surgical procedure for TCS patients and laminectomy/laminotomy associated with the tumor removal was the technique used for the SIT patients (Figure 2). Laminotomy was preferred for children and multilevel tumors while laminectomy was selected for small SITs. Section of the fibrous bands, removal of bony septums, and cutting the filum terminale (FT) were the surgical techniques for TCS patients. In SCM patients, the bony septum/ fibrocartilaginous septum was removed with microsurgical techniques and the FT was also cut under intraoperative neuromonitoring (IN). IN was used in all cases.

SSEPs obtained within the first week after surgery was defined as "early postoperative SSEP", and between the

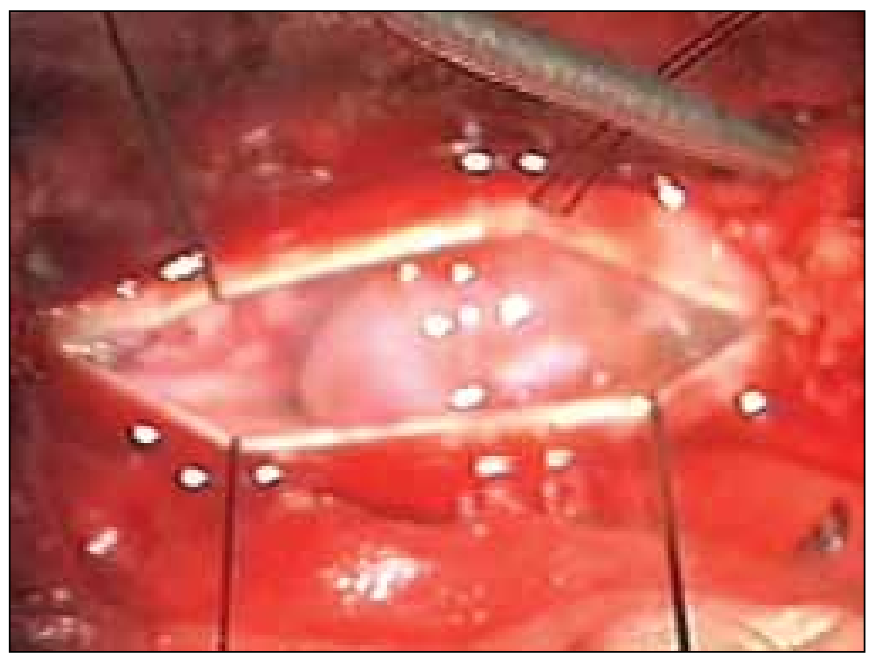

Figure 2: Intraoperative view of a patient with schwannoma.
1-3 months after surgery was defined as "late postoperative SSEP". Median and tibial nerve latencies were separately measured as milliseconds (ms) for both upper and lower extremities and compared based on the diagnosis of the patients. Preoperative, early and postoperative values of left median (LM), left tibial (LT), right median (RM) and right tibial (RT) were also compared. The Statistical Package for the Social Sciences (SPSS) was used for the statistical analysis. Preoperative and postoperative electrophysiological values were compared using the Friedman test. The Wilcoxon test was used for paired groups in order to understand the cause of difference in SSEPs values between the preoperative and postoperative periods. Comparison of the groups based on the diagnosis was done with the Kruskal-Wallis test.

\section{RESULTS}

A total of 30 patients were included this study. Demographic features of the patients are shown in Table I. Five cases were children and 25 were adults. The oldest patient was 67 years old and the youngest was 2 years old (mean age: 27.8 years). Eighteen $(60 \%)$ patients had SIT and underwent tumor excision. Twelve (40\%) patients had TCS and underwent untethering of the spinal cord (Table II). The mean follow-up was 38 months and ranged between 24 and 48 months. The locations of the tumors in SIT patients were as follows: 9 in the lumbar region, 4 in the cervical, 3 in the thoracic, one in the thoracolumbar and one in the cervicothoracic region. The histological diagnosis was ependymoma in 6 cases, schwannoma in 3, meningioma in 3 cases, pilocytic astrocytoma in one, epidermoid tumor in one, lipoma in one, ependymal cyst in one, paraganglioma in one, and metastasis in one patient. The cause of TCS was SCM in 7 patients (Figure $3 \mathrm{~A}, \mathrm{~B}$ ), previous spinal surgery (myelomeningocele, meningocele) in 4 patients and dermal sinus tract in one patient.

There was no neurological deterioration in any patient after surgery.

The minimum and maximum median and tibial nerve latencies, and comparison of all the patients are shown in Table III. The changes in median and tibial nerve latencies in the preoperative, early and postoperative periods based on the surgical intervention are shown in Table IV.

There was a statistically significant difference between preoperative, and early and late postoperative SSEP values (Table III). RT and LT latencies were prolonged in the early

Table I: Demographic Features of the Patients

\begin{tabular}{|c|c|c|c|c|}
\hline & Number & $\%$ & & \\
\hline \multicolumn{5}{|l|}{ Gender } \\
\hline Female & 6 & 20 & & \\
\hline \multirow[t]{2}{*}{ Male } & 24 & 80 & & \\
\hline & Minimum & Maximum & $\overline{\mathbf{x}}$ & SD \\
\hline Age (Years) & 2 & 67 & 27.83 & 15.09 \\
\hline
\end{tabular}

$\bar{X}$ : Average, SD: Standard deviation. 

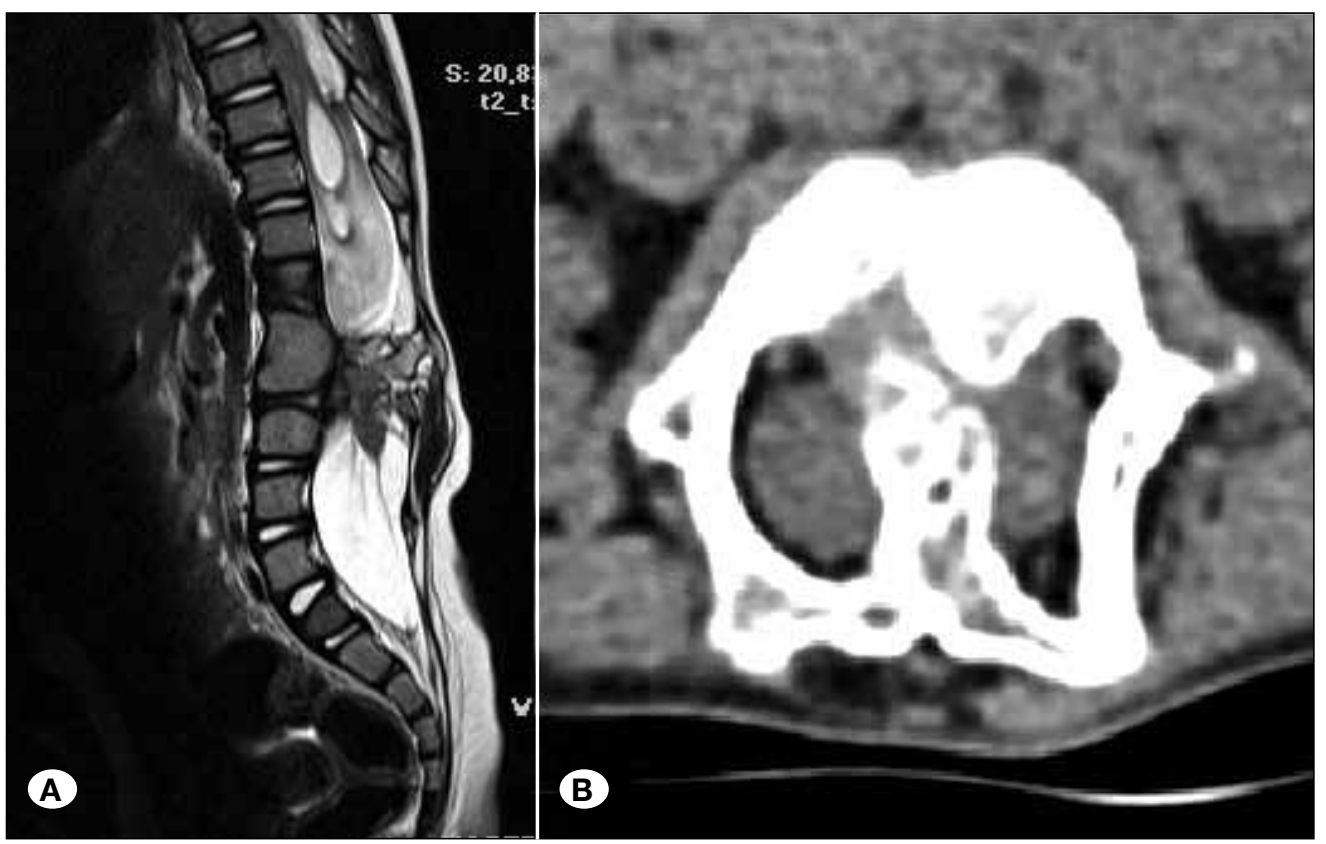

Figure 3: Sagittal MRI scan of a child with type 1 split cord malformation shows bony septum at L1-L2 level associated with syringomyelia and tethered cord syndrome (TCS) (A). Axial CT scan confirms a thick bony septum (B).

Table II: Distribution of the Surgical Procedures

\begin{tabular}{lcc}
\hline Procedure & Number & $\%$ \\
\hline Untethering the spinal cord & 12 & 40 \\
\hline Tumor excision & 18 & 60 \\
\hline Total & 30 & 100 \\
\hline
\end{tabular}

postoperative period, but shortened in the late postoperative period. Contrary, RM and LM latencies were shortened in the early postoperative period, but prolonged in the late postoperative period.

The Wilcoxon test was performed for paired groups in order to determine the cause of the difference between the preoperative and postoperative periods. For preoperative values, it was derived from RT-RM $(p=0.000)$, LT-RM $(p=0.000)$, LM-RT $(p=0.000), L M-L T(p=0.000)$ latency measurements. For early postoperative values, it was derived from RT-RM $(p=0.000)$, LT-RM ( $p=0.000), \operatorname{LM}-R T(p=0.000), \operatorname{LM}-\mathrm{LT}(p=0.000)$ latency measurements. For late postoperative values, it was derived from RT-RM $(p=0.005)$, LT-RM $(p=0.005)$, LM-RT $(p=0.005)$, LM-LT $(p=0.005)$ measurements.

The preoperative and postoperative SSEPs values were compared based on the surgical intervention and no statistically significant difference was detected between the groups (Table IV).

\section{DISCUSSION}

In this study, we compared the postoperative electrophysiological changes in patients with TCS and SIT and we found a significant difference between preoperative, and early and late postoperative SSEP values. Tibial nerve latencies were prolonged in the early postoperative, but shortened in the
Table III: Comparison of Preoperative, Early and Late Postoperative SSEPs Values (ms)

\begin{tabular}{|c|c|c|c|c|c|}
\hline & Min & Max & $\overline{\mathbf{x}}$ & SD & $\mathbf{p}$ \\
\hline \multicolumn{5}{|c|}{ Preoperative SSEP values (ms) } & \multirow{18}{*}{0.003} \\
\hline $\mathrm{RM}$ & 16.20 & 20.10 & 18.72 & 0,99 & \\
\hline $\mathrm{RT}$ & 27.10 & 48,10 & 38,60 & 4.60 & \\
\hline LM & 16.20 & 21.40 & 18.74 & 1.25 & \\
\hline LT & 19.60 & 53.40 & 38.73 & 6.14 & \\
\hline $\mathbf{p}$ & \multicolumn{4}{|c|}{0.000} & \\
\hline \multicolumn{5}{|c|}{ Early Postoperative SSEP values (ms) } & \\
\hline $\mathrm{RM}$ & 16.40 & 20.30 & 18.64 & 1.11 & \\
\hline RT & 33.70 & 46.80 & 39.54 & 3.08 & \\
\hline LM & 15.70 & 21.50 & 18.57 & 1.41 & \\
\hline LT & 33.70 & 54.20 & 40.32 & 4.81 & \\
\hline $\mathbf{p}$ & \multicolumn{4}{|c|}{0.000} & \\
\hline \multicolumn{5}{|c|}{ Late Postoperative SSEP values (ms) } & \\
\hline RM & 18.10 & 20.00 & 18.99 & 0.64 & \\
\hline $\mathrm{RT}$ & 34.60 & 42.10 & 38.49 & 2.66 & \\
\hline LM & 18.10 & 29.90 & 19.91 & 3.54 & \\
\hline LT & 34.60 & 41.80 & 38.34 & 2.40 & \\
\hline $\mathbf{p}$ & \multicolumn{4}{|c|}{0.000} & \\
\hline
\end{tabular}

Friedman test

RM: Right median nerve, LM: Left median nerve, LT: Left tibial nerve, RT: Right tibial nerve, SD: Standard deviation, ms: milliseconds, Min: Minimum, Max: Maximum. 
Table IV: Comparison of the Changes in SSEPs Values (ms) Based on the Type of Surgical Intervention

\begin{tabular}{|c|c|c|c|c|c|c|c|c|}
\hline & \multicolumn{4}{|c|}{ Untethering the spinal cord (TCS) } & \multicolumn{4}{|c|}{ Tumor excision (SIT) } \\
\hline & Min & Max & $\overline{\mathbf{X}}$ & SD & Min & Max & $\overline{\mathbf{X}}$ & SD \\
\hline Preop. RM & 18.40 & 19.30 & 18.96 & 0.37 & 16.20 & 20.10 & 18.65 & 2.00 \\
\hline $\mathrm{p}$ & \multicolumn{8}{|c|}{0.859} \\
\hline Early Postop. RM & 16.40 & 19.00 & 18.23 & 0.93 & 16.50 & 20.30 & 18.81 & 1.22 \\
\hline $\mathrm{p}$ & \multicolumn{8}{|c|}{0.234} \\
\hline Late Postop. RM & 18.10 & 19.50 & 18.64 & 0.59 & 18.70 & 20.00 & 19.34 & 0.50 \\
\hline $\mathrm{p}$ & \multicolumn{8}{|c|}{0.090} \\
\hline Preop. RT & 27.10 & 48.10 & 37.87 & 6.12 & 33.70 & 47.10 & 39.10 & 3.25 \\
\hline$p$ & \multicolumn{8}{|c|}{0.834} \\
\hline Early Postop. RT & 33.90 & 46.80 & 39.93 & 4.15 & 33.70 & 42.80 & 39.36 & 2.67 \\
\hline$p$ & \multicolumn{8}{|c|}{0.965} \\
\hline Late Postop. RT & 35.00 & 42.10 & 38.02 & 2.79 & 34.60 & 41.00 & 39.06 & 2.69 \\
\hline $\mathrm{p}$ & \multicolumn{8}{|c|}{0.465} \\
\hline Preop. LM & 18.20 & 19.80 & 18.96 & 0.62 & 16.20 & 21.40 & 18.66 & 1.50 \\
\hline$p$ & \multicolumn{8}{|c|}{0.724} \\
\hline Early Postop. LM & 16.40 & 19.20 & 18.38 & 1.07 & 15.70 & 21.50 & 18.68 & 1.62 \\
\hline$p$ & \multicolumn{8}{|c|}{0.455} \\
\hline Late Postop. LM & 18.10 & 19.20 & 18.76 & 0.45 & 18.20 & 29.90 & 21.06 & 1.50 \\
\hline $\mathrm{p}$ & \multicolumn{8}{|c|}{0.600} \\
\hline Preop. LT & 27.00 & 53.40 & 38.32 & 6.92 & 19.60 & 45.70 & 39.00 & 5.75 \\
\hline$p$ & \multicolumn{8}{|c|}{0.492} \\
\hline Early Postop. LT & 34.80 & 50.70 & 40.85 & 5.30 & 33.70 & 54.20 & 40.11 & 4.79 \\
\hline $\mathrm{p}$ & \multicolumn{8}{|c|}{0.967} \\
\hline Late Postop. LT & 34.60 & 41.80 & 38.13 & 2.74 & 35.30 & 40.40 & 38.58 & 2.21 \\
\hline $\mathrm{p}$ & \multicolumn{8}{|c|}{0.784} \\
\hline
\end{tabular}

Kruskall Wallis test

RT: Right tibial nerve, LT: Left tibial nerve, TCS: Tethered cord syndrome, SIT: Spinal intradural tumor, Preop: Preoperative, Postop: Postoperative, SD: Standard deviation, X: Average, Min: Minimum, Max: Maximum.

late postoperative period. In contrast, median nerve latencies were shortened in the early postoperative, but prolonged in the late postoperative period. There was no statistically significant difference between the TCS and SIT groups based on the surgical intervention.

TCS and spinal tumors are the clinical entities in which the treatment is mostly performed by neurosurgeons/spine surgeons. Although they are different clinical and radiological conditions, surgical management is mostly preferred for the treatment. TCS is a clinical syndrome that may manifest with neurological or urological symptoms (23). Motor weakness in the lower extremities, urinary disturbances, back pain and foot deformities are the most prominent findings of TCS (13$16,23,27)$. Cutaneous findings may be indicative for SCM which is a part of primary TCS (10). Dermal sinus tracts may also be associated with TCS (23).

SSEPs provides an objective measurement of function in large diameter myelinated sensory afferents peripherally and in the proprioceptive pathway centrally (5). Changes in the amplitude and latency help to localize lesions in the nervous system $(6,11)$. SSEPs have been used in the diagnosis and follow-up of the patients with TCS and spinal tumors for many years $(11,12,18,19,24)$. Preoperative SSEPs give brief information about the integrity of the somatosensory pathways and may 
be play a role in decision-making for surgery in patients with TCS $(16,23)$. Electrophysiological studies in spinal pathologies such as spinal dysraphisms are generally performed in childhood and these studies usually consist of preoperative and postoperative findings $(5,6)$. Most of the papers on the electrophysiological assessments of the TCS or spinal tumors deal with intraoperative monitoring $(12,18,19,25,26,28)$ and few studies have been performed on the effectiveness of electrophysiological studies on decision-making or follow-up of the patients with TCS or spinal tumor (15).

Preoperative SSEPS and MEPs contribute to collecting information about the neurological condition of the patients. This information may provide evidence of TCS or a spinal tumor. Although the present gold standard is clinical and radiological evaluation, neurophysiological studies are also helpful in the diagnosis and follow-up of the patients with these pathologies. Recently, Leung et al. (15) performed a retrospective study on the utility of neurophysiology in the diagnosis of TCS and they found that neurophysiological testing could be a useful adjunct in the diagnosis of TCS, especially for asymptomatic or clinically stable patients. In our study, similar to those of Leung et al., we used median and tibial SSEPs for preoperative electrophysiological evaluation and postoperative follow-up of the patients with TCS and SIT. We also used these SSEPs for intraoperative monitoring, but we did not collect the data of intraoperative monitoring for comparison of the groups. Early SSEPs were recorded within the 7 days after surgery and late postoperative SSEPs were recorded 1-3 months after the surgery. These records were used in the neurological assessments of the patients to determine the effectiveness of surgery. We compared the preoperative, early and late postoperative records and analyzed our results.

Spinal tumors make up a small part of nervous system tumors (24). However, they may cause significant morbidity when inappropriately managed by the surgeon $(3,7)$. These tumors are mostly located in the intradural space and divided into 2 groups as intramedullary and extramedullary. Most SIT cases are extramedullary tumors such as meningiomas and schwannomas (24). Intramedullary tumors are relatively rare and more common in childhood (3). Back pain, motor and sensory deficits and urinary disturbances are the main symptoms of SIT (24). The gold standard for the diagnosis of SIT is MRI and surgery is the main treatment method. The goal of surgery is to remove the tumor as much as possible without any additional neurological deficit $(21,22)$. Sometimes neurological examination may be subjective and depends on the experience of the surgeon. However, electrophysiological tests are more objective then the neurological examination if they are performed and interpreted by the same electrophysiologist. Therefore, we used median and tibial SSEPs as a standard protocol for evaluation of the patients in early and late postoperative periods. In our series, 18 patients had SIT and most of them were ependymoma, schwannoma and meningioma. The most common location was the lumbar spine. In addition, 12 patients had TCS and they had SCM, dermal sinus tract and previous myelomeningocele surgery. Besides the preoperative and postoperative SSEPs, we also used intraoperative neuromonitoring for all patients.
There are some limitations of our study. First of all, this is a retrospective study and there was no control group. Secondly, MEPs were not recorded in all of our patients because of technical difficulties. Finally, lack of long-term follow-up results for all patients is another limitation of our study.

\section{CONCLUSION}

TCS and SIT are not the same clinical entities, but electrophysiological studies show similar results. SSEPs provide valuable information about the somatosensory pathways and this will help the surgeon in decision-making regarding surgical treatment. Further clinical studies with other electrophysiological modalities are needed to obtain better information on the effects of surgery in these patients.

\section{ACKNOWLEDGEMENTS}

We are grateful to Dr. Gulsah KOSE for the statistical analysis of the data and to the Department of Neurology for the electrophysiological tests of our patients.

\section{- REFERENCES}

1. Akay KM, Izci Y, Baysefer A, Timurkaynak E: Split cord malformation in adults. Neurosurg Rev 27(2):99-105, 2004

2. Akay KM, Izci Y, Baysefer A: Dorsal bony septum: A split cord malformation variant. Pediatr Neurosurg 36(5):225-228, 2002

3. Baysefer A, Akay KM, Izci Y, Kayali H, Timurkaynak E: The clinical and surgical aspects of spinal tumors in children. Pediatr Neurol 31(4):261-266, 2004

4. Blount JP, Tubbs RS, Wellons JC III, AcakpoSatchivi L, Bauer D, Oakes WJ: Spinal cord transection for definitive untethering of repetitive tethered cord. Neurosurg Focus 23(2):E11, 2007

5. Costa P, Bruno A, Bonzanino M, Massaro F, Caruso L, Vincenzo I, Ciaramitaro P, Montalenti E: Somatosensory and motor evoked potential monitoring during spine and spinal cord surgery. Spinal Cord 45:86-91, 2007

6. Deletis V, Bueno De Camargo A: Interventional neurophysiological mapping during spinal cord procedures. Stereotact Funct Neurosurg 77: 25-28, 2001

7. Epstein FJ, Farmer JP, Freed D: Adult intramedullary spinal cord ependymomas: The result of surgery in 38 patients. J Neurosurg 79: 204-209, 1993

8. Garces-Ambrossi GL, McGirt MJ, Samuels R, Sciubba DM, Bydon A, Gokaslan ZL, Jallo Gl: Neurological outcome after surgical management of adult tethered cord syndrome. J Neurosurg Spine 11: 304-309, 2009

9. Hudgins RJ, Gilreath CL: Tethered spinal cord following repair of myelomeningocele. Neurosurg Focus 16(2):E7, 2004

10. Izci Y, Gonul M, Gonul E: The diagnostic value of skin lesions in split cord malformations. J Clin Neurosci 14(9):860-863, 2007

11. Kothbauer KF, Deletis V: Intraoperative neurophysiology of the conus medullaris and cauda equina. Childs Nerv Syst 26:247253, 2010 
12. Krassioukov AV, Sarjeant R, Arkia H, Fehling MG: Multimodality intraoperative monitoring during complex lumbosacral procedures: Indications, techniques, and long-term follow-up review of 61 consecutive cases. J Neurosurg (Spine 1) 3:243253, 2004

13. Kural C, Solmaz I, Pusat S, Kırık A, Kaya S, Temiz C, Izci Y: Surgical technique for split cord malformations: Pitfalls and solution pathways. Gulhane Med J 55(2):77-83, 2013 (in Turkish)

14. Lee GY, Paradiso G, Tator CH, Gentili F, Massicotte EM, Fehlings MG: Surgical management of tethered cord syndrome in adults: Indications, techniques, and long-term outcomes in 60 patients. J Neurosurg Spine 4:123-131, 2006

15. Leung V, Pugh J, Norton JA: Utility of neurophysiology in the diagnosis of tethered cord syndrome. J Neurosurg Pediatr 15(4): $\quad 434-437,2015$

16. Lew SM, Kothbauer KF: Tethered cord syndrome: An updated review. Pediatr Neurosurg 43:236-248, 2007

17. Manzano G, Green BA, Vanni S, Levi AD: Contemporary management of adult intramedullary spinal tumors-pathology and neurological outcomes related to surgical resection. Spinal Cord 46: 540-546, 2008

18. Nuwer MR: The multicenter outcome survey for spinal cord monitoring: Monitoring reduces neurological deficits. In: Stalberg E, Sharma HS, Olsson Y (eds), Spinal Cord Monitoring. New York: Springer Verlag Wien, 1998:479-489

19. Oz O, Ulas UH, Duz B, Yucel M, Odabasi Z: Electrophysiological findings in patients with adult tethered cord syndrome. Turk Neurosurg 20(1):16-20, 2010

20. Pouratian N, Elias WJ, Jane JA Jr, Phillips LH 2nd, Jane JA Sr: Electrophysiologically guided untethering of secondary tethered spinal cord syndrome. Neurosurg Focus 29(1):E3, 2010
21. Quiñones-Hinojosa A, Gulati M, Lyon R, Gupta N, Yingling C: Spinal cord mapping as an adjunct for resection of intramedullary tumors: Surgical technique with case illustrations. Neurosurgery 51:1199-1207, 2002

22. Shrivastava RK, Epstein FJ, Perin NI, Post KD, Jallo GI: Intramedullary spinal cord tumors in patients older than 50 years of age: Management and outcome analysis. J Neurosurg Spine 2:249-255, 2005

23. Solmaz I, Izci Y, Albayrak B, Cetinalp E, Kural C, Sengul G, Gocmez C, Pusat S, Tuzun Y: Tethered cord syndrome in childhood: Special emphasis on the surgical technique and review of the literature with our experience. Turk Neurosurg 21(4):516-521, 2011

24. Temiz C, Kural C, Kırık A, Pusat S, Secer HI, Gonul E, Izci $Y$ : Spinal tumors and outcomes of surgical treatment: A retrospective study. Firat Med J 16(4):179-185, 2011 (in Turkish)

25. Torre M, Planche D, Louis-Borrione C, Sabiani F, Lena G, Guys JM: Value of electrophysiological assessment after surgical treatment of spinal dysraphism. J Urol 168(4 Pt 2):1759-1762, 2002

26. Von Koch CS, Quinones-Hinojosa A, Gulati M, Lyon R, Peacock WJ, Yingling CD: Clinical outcome in children undergoing tethered cord release utilizing intraoperative neurophysiological monitoring. Pediatr Neurosurg 37: 81-86, 2002

27. Yamada S, Lonser RR: Adult tethered cord syndrome. J Spinal Disord 13: 319-323, 2000

28. Yanni DS, Ulkatan S, Deletis V, Barrenechea IJ, Sen C, Perin $\mathrm{NI}$ : Utility of neurophysiological monitoring using dorsal column mapping in intramedullary spinal cord surgery. J Neurosurg Spine 12:623-628, 2010 